\title{
Controlled co-immobilization of EGF and VEGF to optimize vascular cell survival
}

Pauline Lequoy $^{\mathrm{a}}$, Frederic Murschel ${ }^{\mathrm{b}}$, Benoit Liberelle ${ }^{\mathrm{b}}$, Sophie Lerouge ${ }^{\mathrm{a}^{*}}$ and Gregory De Crescenzo ${ }^{\text {b* }}$

a Research Centre, Centre Hospitalier de l’Université de Montréal (CRCHUM), 900 St Denis, Tour Viger, Montréal (QC), Canada H2X 0A9.

and

Department of Mechanical Engineering, École de technologie supérieure (ÉTS). 1100 boul. Notre-Dame Ouest, Montréal (QC), Canada H3C 1K3.

b Department of Chemical Engineering, École Polytechnique de Montréal. P.O. Box 6079, succ. Centre-Ville, Montréal (QC), Canada H3C 3A7.

(*) Corresponding authors

Sophie Lerouge

E-mail: Sophie.lerouge@etsmtl.ca; Tel: +1 514 396-8836; Fax: +1 5144127785.

Gregory De Crescenzo

E-mail: gregory.decrescenzo@polymtl.ca; Tel: +1 5143404711 (\#7428); Fax: +1 514 3402990. 


\section{ABSTRACT}

Growth factors (GFs) are potent signaling molecules that act in a coordinated manner in physiological processes such as tissue healing or angiogenesis. Co-immobilizing GFs on materials while preserving their bioactivity still represents a major challenge in the field of tissue regeneration and bioactive implants. In this study, we explore the potential of an oriented immobilization technique based on two high affinity peptides, namely the Ecoil and Kcoil, to allow for the simultaneous capture of the epidermal growth factor (EGF) and the vascular endothelial growth factor (VEGF) on a chondroitin sulfate coating. This glycosaminoglycan layer was selected as it promotes cell adhesion but reduces non-specific adsorption of plasma proteins. We demonstrate here that both Ecoiltagged GFs can be successfully immobilized on chondroitin sulfate surfaces that had been pre-decorated with the Kcoil peptide. As shown by direct ELISA, changing the incubation concentration of the various GFs enabled to control their grafted amount. Moreover, cell survival studies with endothelial and smooth muscle cells confirmed that our oriented tethering strategy preserved GF bioactivity. Of salient interest, coimmobilizing EGF and VEGF led to better cell survival compared to each GF captured alone, suggesting a synergistic effect of these GFs. Altogether, these results demonstrate the potential of coiled-coil oriented GF tethering for the co-immobilization of macromolecules; it thus open the way to the generation of biomaterials surfaces with fine-tuned biological properties.

\section{KEYWORDS}

Surface functionalization, Co-immobilization, Growth Factor, Oriented tethering, Cell survival 


\section{INTRODUCTION}

Conferring bioactive properties to synthetic materials via specific signaling molecules such as growth factors is a promising way to predict and control biological response to implants. Growth factors (GFs) are naturally present in the body as soluble or extracellular matrix (ECM)-bound cues for the cells. Accordingly, many efforts have been dedicated to incorporate GFs into materials in order to take advantage of their natural regenerative action either via their progressive release[1-3] or their immobilization on various substrates.[4-6] Such GF-modified biomaterials have been shown to promote in vitro cell proliferation,[7, 8] migration [8, 9] and differentiation.[10, 11]

However, most of the studies on the biological modification of materials rely on the addition of a single GF, while in their physiological environment, GFs are often combined, and complex processes such as wound healing or angiogenesis typically involve several signalling proteins possessing synergistic or complementary actions.[1215] This generated a growing interest in biomimetic materials delivering or displaying multiple GFs.[15-18] Studies have shown that GF combination in biomaterials can improve angiogenesis,[17, 19-22] osteogenesis,[23] directed migration[24] or cell differentiation[23] when compared to a single GF. However, major hurdles still limit the use of systems involving multiple GF, such as the huge quantities of GF required for large size implants/scaffolds, or the lack of characterization of potential synergies existing between GF that could be exploited for enhanced implant biological activity. The search towards an efficient, well-controlled immobilization platform for GF combination is thus still in progress. 
To reach that aim, stable immobilization appears advantageous since it provides the substrate with a high local concentration of GF that is not released over time, thereby inducing an enhanced and sustainable cell response compared to free growth factor.[2527] Moreover, lower amounts of immobilized GFs are required to trigger cell stimulation when compared to their supply in a diffusible form, given that large quantities need to be provided by a sustainable source (either medium renewal in vitro or controlled release).[28] Finally, for blood-contacting devices, stable immobilization enables a localized and durable effect [25] as it prevents GF release into the blood stream. Another challenge is the choice of GF immobilization method to preserve its biological activity. Electrostatic binding can alter protein structure and negatively impact GF bioactivity as a result of denaturation and/or a random presentation on the surface, with active sites not being fully accessible for recognition by cell surface receptors.[29] Furthermore, in physiological conditions, the long term availability of the GF may also be limited due to the weak attachment of molecules on the surface.[29] Covalent immobilization involving irreversible binding of reactive groups present on side chain residues to chemical moieties available at the surface is durable but can also lead to loss of bioactivity due to conformational changes and random orientation of the GF upon grafting.[5, 29]

In this context, several groups have developed site-specific, oriented protein tethering systems that maintain GF bioactivity. Those include the use of ECM binding tags that can be genetically fused to GFs, as well as pairs of high affinity peptides with variable stabilities in which one peptide is bound to the substrate of interest while the other is fused to GFs by genetic engineering.[17, 30-33] On that note, we have investigated the potential of two peptides, the Ecoil and Kcoil, of respective amino acid sequence 
[EVSALEK $_{5}$ and $[\mathrm{KVSALKE}]_{5}$ that bind to each other to form stable coiled-coil structures.[34] Ecoil/Kcoil mediated capture has been successfully applied to tether various Ecoil-tagged GFs, such as the epidermal growth factor (EGF)[35] and the vascular endothelial growth factor (VEGF),[36] onto substrates that had been predecorated with Kcoil peptides. Careful positioning of the Ecoil tags on the chimeras corresponding to each GF allowed this immobilization strategy to preserve the GF bioactivity after tethering (as deduced from receptor activation,[34] increase in adhesion[27], proliferation[27] or survival [36, 37] of cells). Of interest, coiled-coil immobilized and free EGF and VEGF led to comparable cell survival when provided at sufficiently high doses.[36, 37]

Although this system had been limited so far to the immobilization of a single type of GF at a time, we hypothesized that Kcoil-bearing substrates could readily be functionalized with multiple Ecoil-tagged GFs. The objective of this work was therefore to investigate the feasibility of GF co-immobilization, its control and the advantage of the stable coiled-coil capture system as a platform to investigate the collaborative effect between GFs and its potential to create a coating with tailored properties. More specifically, we hypothesized that a controlled combination of EGF and VEGF could help to optimize a coating with pro-survival properties. Indeed, conferring pro-survival properties to biomaterials is an ongoing challenge for several applications such as tissue engineered scaffolds where survival of pre-seeded cells is crucial to counter the cell loss caused by serum deprivation and hypoxia before neo-angiogenesis takes place. [38, 39] Healing around stent grafts implanted during endovascular repair of abdominal aortic 
aneurysms may also benefit from pro-survival properties as the vessel wall in aneurysms displays strong vascular cell depletion due to a pro-apoptotic environment.[40, 41]

To achieve this aim, Ecoil-tagged EGF and Ecoil-tagged VEGF (hereafter designated as E-EGF and E-VEGF, respectively) were co-immobilized using coiled-coil mediated tethering on chondroitin sulfate (CS). When coated on biomaterial's surfaces, this ECM glycosaminoglycan was shown to permit cell adhesion despite low-fouling properties and low-platelet adhesion,[42, 43] suggesting that it could enhance the bioavailability of the immobilized GF. In an effort to evaluate the potential of a dual GF immobilization for vascular and tissue engineering applications, the effect of surface densities of these GFs (alone and combined), on the survival of two vascular cell types - the human umbilical vein endothelial cells (HUVEC) and human aortic smooth muscle cells (AoSMC) was studied. 


\section{MATERIALS AND METHODS}

\subsection{Materials and Reagents}

Chondroitin-4-sulfate (CS), sodium chloride (99.99\% purity), 1-Ethyl-3-(3dimethylaminopropyl)-ethylcarbodiimide hydrochloride (EDC), N-hydroxysuccinimide (NHS), 2-morpholinoethane sulfonic acid (MES), Dulbecco's Phosphate Buffered Saline (modified PBS, without calcium chloride and magnesium chloride), Tween 20, Cysteine (99+\% purity) and resazurin sodium salt were purchased from Sigma-Aldrich (Oakville, ON). EMCH (3,3'-N-[ع-maleimidocaproic acid] hydrazide, trifluoroacetic acid salt) was purchased from Pierce Biotechnology (Rockford, IL). Commercially available DuoSet ELISA kits containing biotinylated goat anti-hEGF antibody and mouse anti-hVEGF 165 antibody and detection antibodies, streptavidin-horseradish peroxidase (streptavidinHRP), bovine serum albumin (BSA), substrate solution (hydrogen peroxide/tetramethylbenzidine) was obtained from R\&D Systems (Minneapolis, MN). CellBIND $^{\circledR}$ carboxyl-exposing microplates (96-well) were purchased from Corning (Corning, NY).

\subsection{Kcoil, Ecoil-tagged EGF and Ecoil-tagged VEGF Production}

Cysteine-tagged Kcoil peptides were synthesized by the peptide facility at University of Colorado (Denver, CO).[35] Ecoil-tagged EGF (E-EGF) and Ecoil-tagged VEGF 165 (E-VEGF) were produced in HEK 293-6E cells and purified by immobilized metal-ion affinity chromatography (IMAC) as previously described.[35] Protein concentration was determined by ELISA. Purified proteins were then stored at $-80^{\circ} \mathrm{C}$ until use. 


\subsection{Chondroitin sulfate and Growth Factor Immobilization}

\section{Chondroitin sulfate coating preparation}

CellBIND $^{\circledR} 96$ well microplates were used as model surfaces to prepare the coatings and carry out the cell culture assays. To create amine groups on the carboxyl-presenting CellBIND surfaces, carbohydrazide $\left(\mathrm{CH}\right.$, chemical formula $\left.\mathrm{NH}_{2}-\mathrm{NH}-\mathrm{CO}-\mathrm{NH}-\mathrm{NH}_{2}\right)$ was grafted using carbodiimide chemistry by exposing the wells to $50 \mu \mathrm{l}$ of a solution containing $50 \mathrm{mM} \mathrm{CH}, 200 \mathrm{mM}$ EDC and $50 \mathrm{mM}$ MES for $2 \mathrm{~h}$ and rinsing with PBS and water (2 min each) in an ultrasonic bath. Aminated wells were then exposed to $50 \mu \mathrm{l}$ of a solution containing $0.01 \mathrm{~g} / \mathrm{ml} \mathrm{CS,} \mathrm{40 \%} \mathrm{v/v} \mathrm{EtOH,} 50 \mathrm{mM}$ MES, $22.8 \mathrm{mM}$ EDC, $4.6 \mathrm{mM}$ NHS for $1 \mathrm{~h}$. The surfaces and the wells were finally rinsed once using PBS (10 mM, pH 7.4) and two times using Milli-Q water for 2 min in an ultrasonic bath.

\section{E-EGF and E-VEGF Capture on Kcoil Layers}

A Kcoil layer was generated on CS-covered surfaces using EMCH linker, that both reacts with the carboxyl groups of CS and the thiol group of the cysteine-terminated Kcoil, as previously described.[37] Briefly, CS was activated using a 40\% v/v EtOH, 50 mM MES, $22.8 \mathrm{mM}$ EDC, $4.6 \mathrm{mM}$ NHS for $10 \mathrm{~min}$. Then, activated CS carboxyl groups were reacted with the primary amine group of EMCH by depositing $50 \mu \mathrm{L}$ of $1 \mathrm{mM}$ EMCH in PBS:DMSO (90:10 v/v) on each surface for $1 \mathrm{~h}$. The surfaces were rinsed using PBS and Milli-Q water. Deactivation of remaining polymer COONHS groups was obtained with $100-\mu \mathrm{L}$ ethanolamine solution ( $1 \mathrm{M}, \mathrm{pH}$ 7.0) for $15 \mathrm{~min}$, followed by rinsing with PBS and Milli-Q water. Thiol-reactive surfaces were then reacted with 100 
$\mu \mathrm{L}$ of $1-\mu \mathrm{M}$ cysteine-tagged Kcoil in Milli-Q water for $1 \mathrm{~h}$. The surfaces were rinsed using PBS and Milli-Q water. Unreacted sites of EMCH were blocked using $100 \mu \mathrm{L}$ of 50-mM cysteine solution (1 $\mathrm{M} \mathrm{NaCl}$ in $0.1 \mathrm{M}$ sodium acetate, $\mathrm{pH} 4.0$ ) followed by rinsing with PBS and Milli-Q water.

Surfaces harboring covalently bound Kcoil were stored overnight in a $10 \%$ solution of fœtal bovine serum (FBS) in PBS. After rinsing with PBS, surfaces were incubated with $50 \mu \mathrm{L}$ of E-EGF and/or E-VEGF solution (at concentrations ranging from 0.05 to $20 \mathrm{nM}$ in $10 \mathrm{mM}$ PBS containing 1\% BSA, PBS-BSA) for $1 \mathrm{~h}$. After the Ecoil-tagged protein(s) capture, wells were rinsed with PBS. For successive captures, after the first coil-tagged GF capture $(1 \mathrm{~h})$, surfaces were rinsed with PBS and incubated with the second coiltagged GF (1 h). The Ecoil-tagged GF immobilization of EGF and VEGF is illustrated in Fig. 1.

\subsection{Surface growth factor quantification by ELISA}

Quantification of EGF and VEGF surface densities in the wells was performed by direct ELISA. The wells were first incubated with $50 \mu \mathrm{L}$ of a biotinylated anti-human EGF antibody or VEGF antibody (50 ng/mL in PBS-BSA) for $30 \mathrm{~min}$. The wells were washed 3 times with PBS containing 0.05\% Tween 20 (PBS-T) and $50 \mu \mathrm{L}$ of a streptavidin-HRP solution (diluted 200 times in PBS-BSA) was added to the wells for 20 min. Finally, the wells were rinsed 3 times with PBS-T and reacted with $50 \mu \mathrm{L}$ of the substrate solution (50:50 v/v mixture of hydrogen peroxide and tetramethylbenzidine). The optical density (O.D.) at $630 \mathrm{~nm}$ was measured using an ELISA plate reader (Victor ${ }^{3} \mathrm{~V}$ Multilabel Counter, PerkinElmer, Woodbridge, ON). The slopes corresponding to the 
O.D. variation in the wells over time were calculated, and the value obtained for a surface with no growth factor was subtracted from all signals.

\subsection{Stability of coiled-coil immobilization}

Growth factor-immobilized samples were incubated either 24 hrs in complete growth medium with 5\% v/v FBS followed by 7 days in serum-free medium (named 8 day treatment in the rest of the manuscript, comparable to AoSMC survival test); or 24 hrs in complete growth medium with 2\% v/v FBS followed by 2 days in serum-free medium (named 3 day treatment in the rest of the manuscript, comparable to HUVEC survival test). Direct ELISA was then performed as presented above and the results are shown relative to a fresh incubation of GF. For all samples, medium was changed every two days to mimic cell culture conditions.

\subsection{Cellular assays}

\section{Cell culture materials}

Human umbilical vein endothelial cells (HUVEC) and human aortic smooth muscle cells (AoSMC) were purchased from LONZA (Walkersville, MD) and cultured in their respective complete medium - Clonetics ${ }^{\mathrm{TM}} \mathrm{EGM}^{\mathrm{TM}}-2$ and SmGM ${ }^{\mathrm{TM}}-2$. Basal EBM ${ }^{\mathrm{TM}}-2$ and $\mathrm{SmBM}^{\mathrm{TM}}-2$ were used as serum-free media for the survival experiments.

\section{Cell survival in serum-free medium}

Cells were seeded in 96-well microplates and incubated on each surface at $37^{\circ} \mathrm{C}$ and $5 \% \mathrm{CO}_{2}$ in $200 \mu \mathrm{L}$ of complete growth medium. Cell seeding densities were 20,000 cells/ well for HUVEC and 10,000 cells/well for AoSMC. After a 24 h-adhesion period, the 
surfaces were rinsed with PBS to detach non-adherent cells. Serum-free medium was then added (200 $\mu \mathrm{L}$ per well) and changed every other day. Cell metabolic activity was probed using a resazurin assay.[44] Once rinsed with PBS, the wells were exposed to a mix of resazurin $(100 \mu \mathrm{g} / \mathrm{mL}$ in MilliQ water) and culture medium (10:90 v:v) for $2 \mathrm{~h}$. Fluorescent signal was read using a spectrophotometer (560 and $590 \mathrm{~nm}$, for excitation and emission wavelengths, respectively). Cells spreading on the well surfaces was also evaluated via nucleus and actin staining.[45] In brief, cells were fixed with a $4 \% \mathrm{w} / \mathrm{v}$ solution of formaldehyde for $10 \mathrm{~min}$ at room temperature and rinsed with PBS. They were then permeabilized with $0.4 \% \mathrm{v} / \mathrm{v}$ Triton X-100 for 10 min and rinsed with PBS. A $10 \%$ FBS solution in $0.1 \% \mathrm{v} / \mathrm{v}$ Triton $\mathrm{X}-100 / \mathrm{PBS}$ was used to block the cells. Actin staining was achieved by incubating phalloidin-Alexa 488 (1/40 dilution, Cat.\# A12379, Molecular Probes, Invitrogen, Grand Island, NY) in PBS for 50 min. Nucleus staining was achieved by adding $10 \mu \mathrm{l}$ of Hoechst solution $(5 \mu \mathrm{g} / \mathrm{ml})$ and incubating another 10 min. Cell spreading was estimated with ImageJ image analysis software.

\subsection{Statistical analysis}

Results are expressed as mean \pm standard deviation. Statistics were assessed by oneway ANOVA with Tukey's HSD post-hoc testing; p-values less than 0.05 were considered significant. 


\section{$3 \quad$ RESULTS}

\subsection{Characterization of immobilized growth factors}

During this study, Kcoil-functionalized CS surfaces were exposed to either E-EGF or E-VEGF alone ('single capture' Fig. 2A), or to a combination of both GFs (Fig. 2B). The co-immobilization of EGF and VEGF was performed by incubating the proteins together ('simultaneous incubation’ Fig. 2B) or one after the other ('sequential incubation’ Fig. 3).

In a first step, E-EGF or E-VEGF was incubated alone on Kcoil-functionalized surfaces at concentrations ranging from 0.1 to $20 \mathrm{nM}$. The range of incubation concentrations was selected after preliminary in vitro cell survival assays. The lowest concentration $(0.1 \mathrm{nM})$ was chosen since no significant impact on cell survival was detected for HUVEC and SMC cultured on surfaces where E-VEGF and E-EGF had been incubated at $0.1 \mathrm{nM}$, respectively. After GF incubation, the optical density (O.D.) corresponding to tethered E-EGF or E-VEGF detected by direct ELISA was measured (Fig. 2A). For both GFs, an O.D. saturation was observed. The saturation occurred for concentrations higher than, or equal to, 1nM for E-VEGF and $5 \mathrm{nM}$ for E-EGF.

The non-specific adsorption of E-EGF and E-VEGF was evaluated by incubating the tagged GFs on CS-coated surfaces (data not shown). Of interest, the O.D. signals of adsorbed GFs were inferior or equal to $20 \%$ of the total signal for immobilized VEGF and less than 5\% for adsorbed EGF, meaning that most of GF molecules were indeed immobilized to Kcoil-coated CS surfaces via coiled-coil interactions (Supplementary Figure 1). 


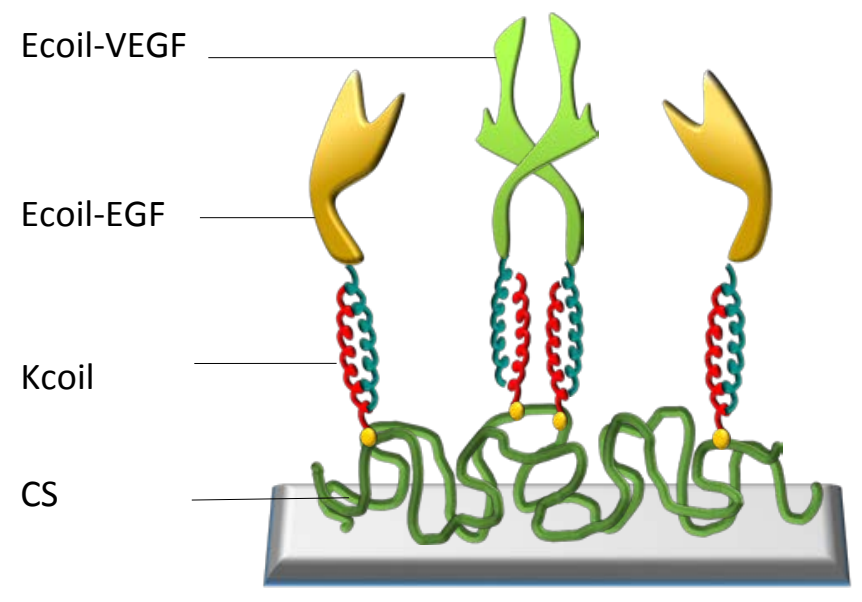

Figure 1. Concept of the Ecoil-tagged EGF (E-EGF, monomeric) and Ecoil-tagged $V E G F$ (E-VEGF, dimeric) co-capture on Kcoil-decorated chondroitin sulfate (CS).

The saturation of ELISA signals observed in Fig. 2A indicates that the final layer of the assay (horseradish peroxidase) reached a maximal density on the surfaces. This could be explained by the GFs reaching themselves a maximal density on the surface, with the immobilized Kcoil peptides being the limiting reagent of the coiled-coil interactions. Another explanation would be that the actual GF density kept increasing with concentrations past $1 \mathrm{nM}$ E-VEGF (resp. $5 \mathrm{nM}$ E-EGF) but that the density of ELISA reagents (antibodies and/or horseradish peroxidase) would not, due to their steric hindrance. To test these hypotheses, a sequential incubation of GFs was performed. A high concentration (20 nM) of E-EGF (resp. E-VEGF) was incubated over a surface previously decorated with varying concentrations of E-VEGF (resp. E-EGF). Direct ELISA results presented in Fig. 3A showed that E-EGF capture was strongly hindered when the surface was previously functionalized with concentrations of E-VEGF of $1 \mathrm{nM}$ and higher, with a complete inhibition of E-EGF capture with a pre-incubation superior to 5 nM E-VEGF. The data thus indicate that Kcoil peptides were saturated when the 
surface was pre-treated with E-VEGF concentrations of $5 \mathrm{nM}$ and higher, and thus that the plateau observed in Fig. 2A was due to E-VEGF reaching a maximal density on the surfaces.

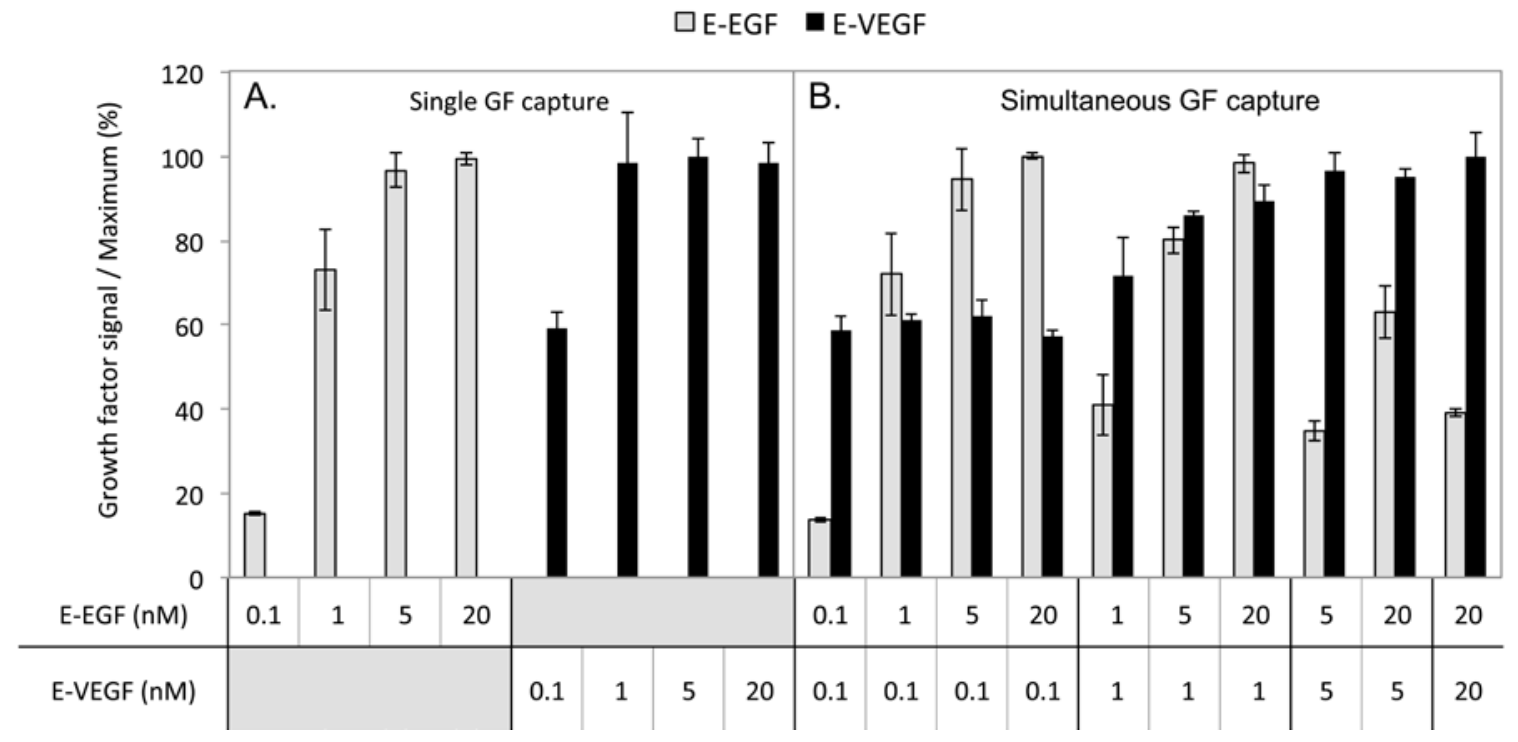

Figure 2. Single capture (A) and simultaneous capture (B) of E-EGF and E-VEGF on Kcoil-functionalized CS surfaces. Relative ELISA signal as a function of growth factor incubation concentrations (Mean $\pm S D, n \geq 8$ ).

In contrast, E-VEGF capture was possible following E-EGF pre-incubation, no matter the E-EGF concentration (Fig. 3B). Of prime interest, the ELISA signals corresponding to E-EGF alone and E-EGF followed by E-VEGF incubation were similar, which indicates that E-VEGF did not displace previously captured E-EGF and that the coiledcoil capture was stable (see stability test in Fig. 4). Altogether, the results demonstrate that a large number of Kcoil peptides remained available for E-VEGF recruitment, and thus that the saturation observed for E-EGF in Fig. 2A was not due to a complete occupation of the Kcoil peptides: E-EGF did not reach maximal density but the ELISA reagents did, which was most likely due to their steric hindrance. 

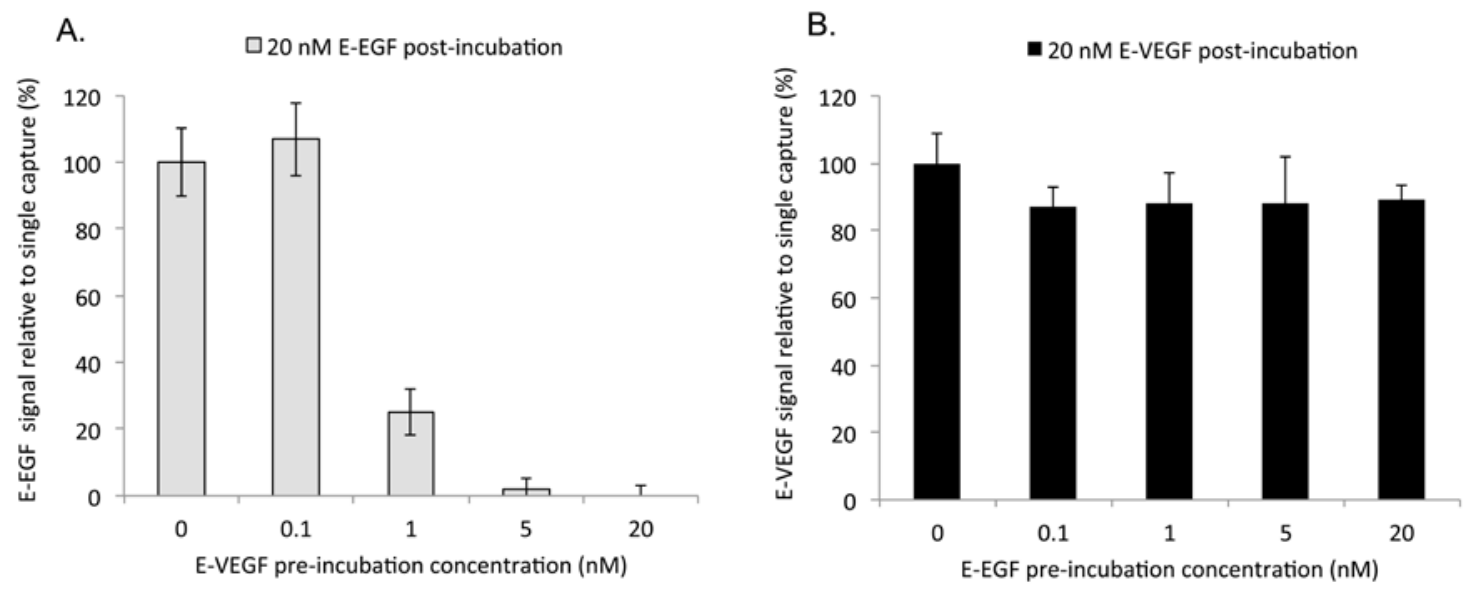

Figure 3. Sequential tethering of (A) $20 \mathrm{nM}$ E-EGF or (B) $20 \mathrm{nM}$ E-VEGF incubated over Kcoil-functionalized CS surfaces that had been pre-incubated with varying concentrations of (A) E-VEGF or (B) E-EGF. The data are presented as ELISA signal relative to a single capture of (A) $20 \mathrm{nM}$ E-EGF and (B) $20 \mathrm{nM}$ E-VEGF (without preincubation).

Simultaneous incubation of E-EGF and E-VEGF was also tested. Corresponding ELISA results (Fig. 2B) showed that varying the incubation concentrations of both GFs resulted in the creation of various ratios of immobilized GFs. Of interest, the ELISA response at a given E-VEGF concentration was not significantly different when this GF was incubated alone (Fig. 2A) or in combination with E-EGF (Fig. 2B). On the contrary, the more E-VEGF in the solution, the less captured E-EGF on the surface. It is here noteworthy that E-VEGF was expressed as a homodimeric protein and thus bears 2 Ecoil tags [46], whereas E-EGF is monomeric and has one Ecoil moiety only.[47] Our observations can therefore be explained by an avidity phenomenon that favors the grafting of E-VEGF over the grafting of E-EGF (Fig. 1). The data obtained here by ELISA are in good agreement with previous surface plasmon resonance assays using Kcoil-decorated sensor chips: E-EGF displayed a steady though slow dissociation under continuous flow from the surfaces and could be regenerated by one pulse of $6 \mathrm{M}$ 
guanidium hydrochloride (GdnHCl) [34]. Oppositely, no dissociation was observed for

E-VEGF. The overwhelming stability of Kcoil-mediated E-VEGF immobilization was further proven by incomplete regeneration after several pulses of $6 \mathrm{M} \mathrm{GdnHCl.[46]}$

A.

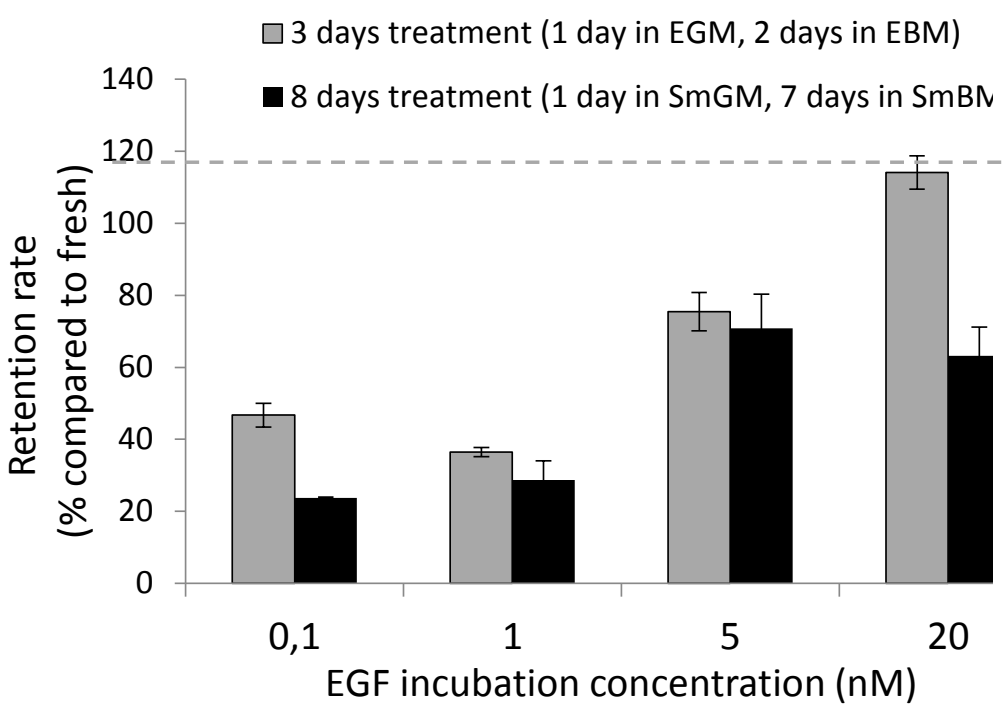

B.

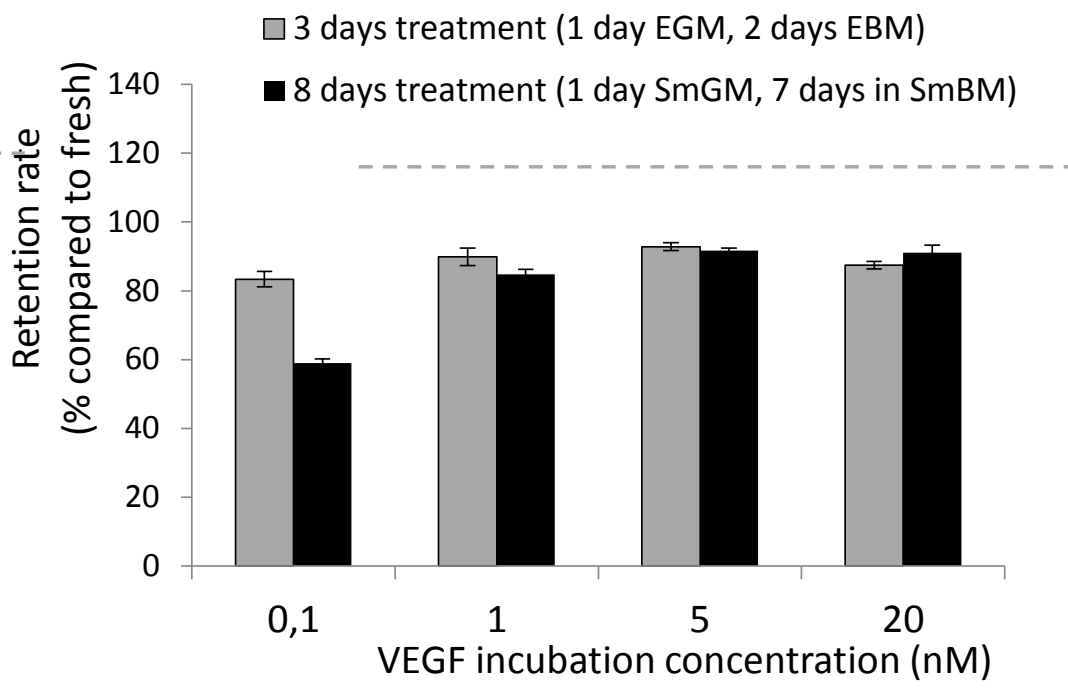

Figure 4. Stability assay. Relative retention rates of E-EGF (A) and E-VEGF (B) after 3day or 8-day treatments in cell culture conditions estimated by direct ELISA. The retention rates of E-EGF and E-VEGF after the ageing treatments are expressed relatively to the signal obtained on fresh surfaces (Mean $\% \pm S D, n \geq 3$ ). 3-day treatment is comparable to HUVEC survival test: 1-day adhesion in complete medium EGM containing 2\% FBS and 2-day survival in basal EBM. 8-day treatment is comparable to AoSMC survival test, 1-day adhesion in complete medium SmGM containing 5\% FBS and 7-day survival in basal SmBM.

The stability of coiled-coil interactions was tested by incubation in cell culture medium in the same conditions as those used for our cell culture experiments, the results are presented in Fig. 4. E-VEGF was stable with a very high retention rate (between 5994\%) of the immobilized growth factor after both the 3-day and the 8-day treatment (comparable respectively to HUVEC or AoSMC survival tests) for incubation 
concentrations ranging from 1 to $20 \mathrm{nM}$. Of interest, the minimum of GF retention of 59\% was observed after the 8-day treatment for E-VEGF incubation concentration of 0.1 nM. E-EGF showed to be less stable than E-VEGF, with retention rates between 23 and 63\% after the 8-day treatment, and between 47 and 114\% after the 3-day treatment. Overall, the fact that E-EGF is less stable than E-VEGF confirms E-VEGF multiple binding to Kcoil-functionalized surfaces (avidity).

\subsection{Bioactivity of immobilized growth factors}

\section{HUVEC}

HUVEC survival on E-EGF- and E-VEGF-decorated surfaces after 2 days in serumfree medium is presented in Fig. 5, and cell morphology on selected surfaces is displayed in Fig. 6.

The 48-h serum deprivation treatment significantly impacted the number of cells on control surfaces (CellBIND ${ }^{\circledR}$ culture plate and carbohydrazide aminated surfaces), as expected.[36] Chondroitin sulfate, although known for its anti-apoptotic properties,[48, 49] did not induce a significant increase in HUVEC survival when compared to the other controls (Fig. 5). On GF-immobilized surfaces, a tremendous difference in trends was observed between the survival induced by E-EGF or by E-VEGF. The maximal survival observed with E-EGF functionalized surfaces was $17 \pm 8 \%$, which was not significantly higher than that on bare CS surfaces $(12 \pm 4 \%, p=0.99)$. In contrast, on E-VEGF functionalized surfaces, cell survival increased progressively from $10 \pm 4 \%$ to $75 \pm 9 \%$ by increasing VEGF incubation concentration from 0.1 to $20 \mathrm{nM}$. 


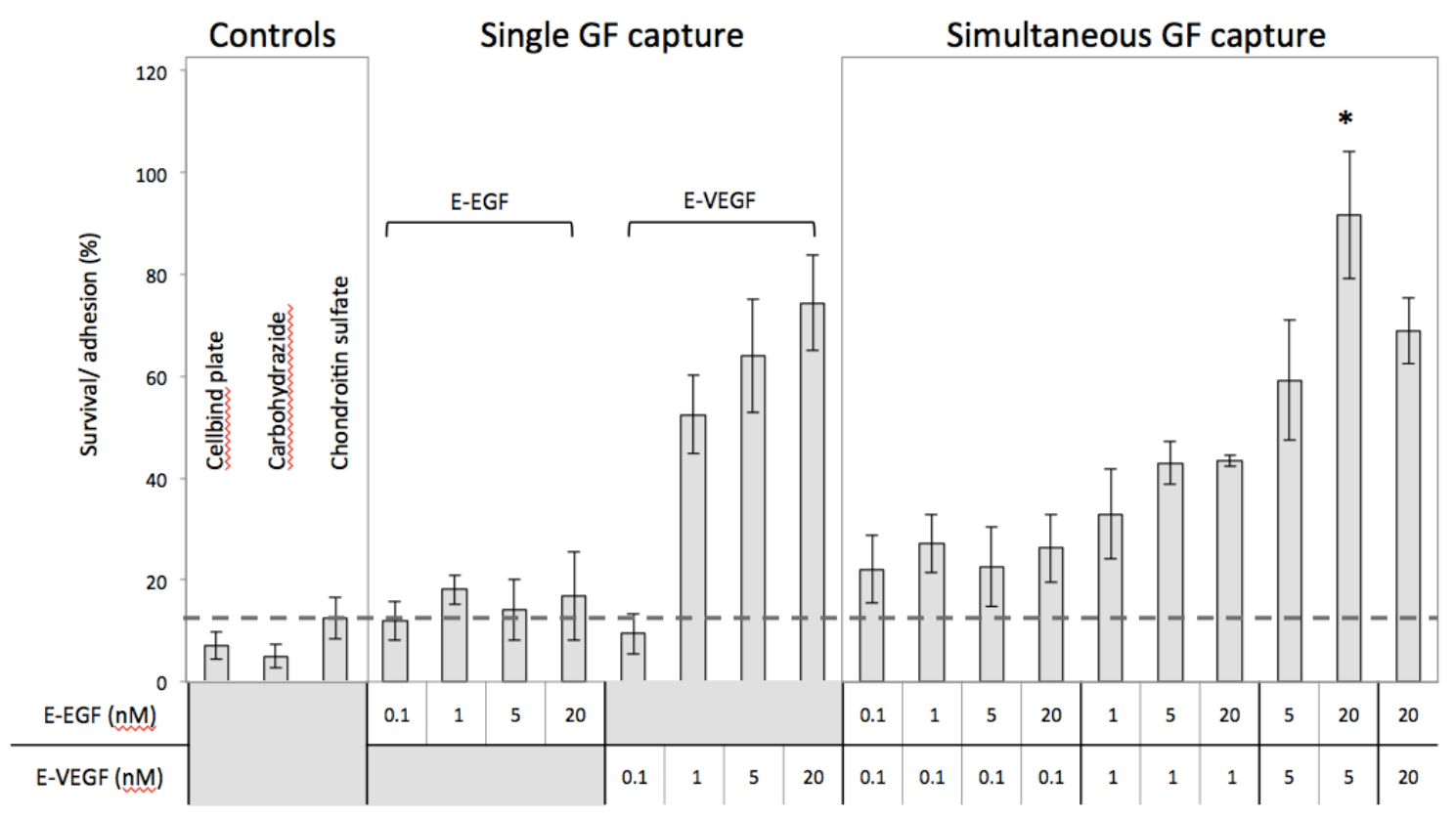

Figure 5. HUVEC survival after 2 days in serum-free medium. Ratio of metabolic activity estimated by resazurin assay at 2 days relative to initial adhesion (Mean $\pm S D ; n=12$ ). *: Statistical difference with all other conditions $(p<0.005)$.

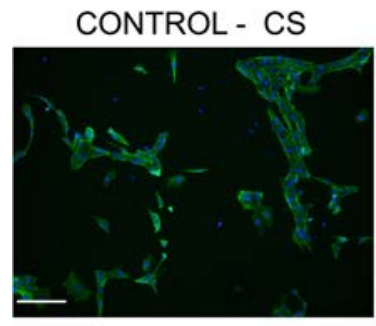

Survival: $12 \%$

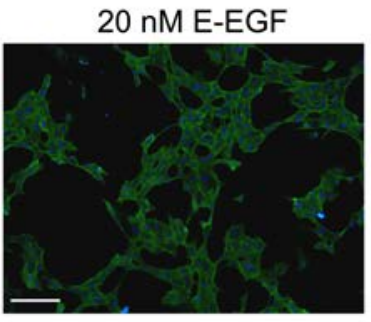

Survival: $17 \%$

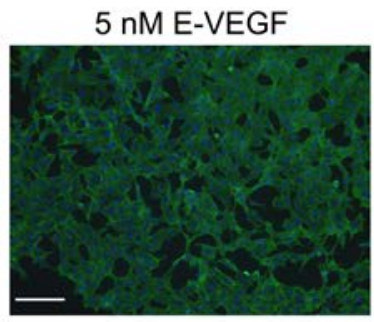

Survival: $74 \%$
$20 \mathrm{nM}$ E-EGF + $5 \mathrm{nM}$ E-

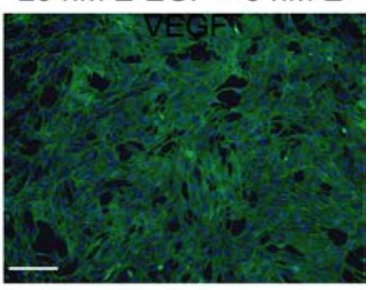

Survival: $92 \%$

Figure 6. Morphology of HUVEC after 2 days in serum-free medium, actin and nucleus staining. Scale bar: $200 \mu \mathrm{m}$.

The best survival (92 $\pm 12 \%$ ) was however observed for surfaces pre-incubated with a mixture of E-EGF (20 nM) and E-VEGF (5 nM), which was statistically higher than all other conditions $(p<0.005)$, including single capture of E-VEGF at $5 \mathrm{nM}(64 \pm 11 \%)$ and of E-EGF at $20 \mathrm{nM}(20 \pm 9 \%)$. These data suggested a synergistic effect of E-EGF 
and E-VEGF on the surfaces exposing the appropriate combination of both GFs, which led to the conservation of a quasi monolayer of HUVEC after the 48-h serum free treatment (Fig 6). Of interest, the mean single cell area was similar on all surfaces (Table 1).

Table 1. HUVEC single cell area after 2 days in serum-free medium (Mean \pm SD; no statistical difference between groups).

\begin{tabular}{|c|c|c|c|c|}
\hline Surface & CS & 20 nM E-EGF & 5 nM E-VEGF & $\begin{array}{c}20 \text { nM E-EGF + } \\
5 \text { nM E-VEGF }\end{array}$ \\
\hline $\begin{array}{c}\text { HUVEC area } \\
\left(\mu \mathrm{m}^{2}\right)\end{array}$ & $1211 \pm 95$ & $1422 \pm 127$ & $1358 \pm 63$ & $1265 \pm 59$ \\
\hline
\end{tabular}

AoSMC

AoSMC survival on surfaces decorated with E-EGF and E-VEGF after 7 days in serum-free medium is presented in Fig. 7, and cell morphology on selected surfaces is shown in Fig. 8.

Similarly to HUVEC, serum-free treatment affected AoSMC survival, however the time needed to get a significant decrease in metabolic activity was much longer than for HUVEC. After 7 days in serum-free conditions, AoSMC retention was similar on our controls and on CS surfaces, showing that anti-apoptotic properties of CS are not sufficient to induce long-term survival. As opposed to HUVEC, E-VEGF immobilization alone showed little enhancement of AoSMC survival (31 $\pm 5 \%$ for surfaces incubated with E-VEGF at $20 \mathrm{nM}$ compared to $20 \pm 7 \%$ for bare CS surfaces). However, as previously reported, the coiled-coil immobilization of E-EGF on CS led to a significant increase in cell survival,[37] and this pro-survival effect increased with the E-EGF 
incubation concentration (from $27 \pm 12 \%$ for 0.1 -nM E-EGF to $53 \pm 9 \%$ for 20 -nM EEGF).

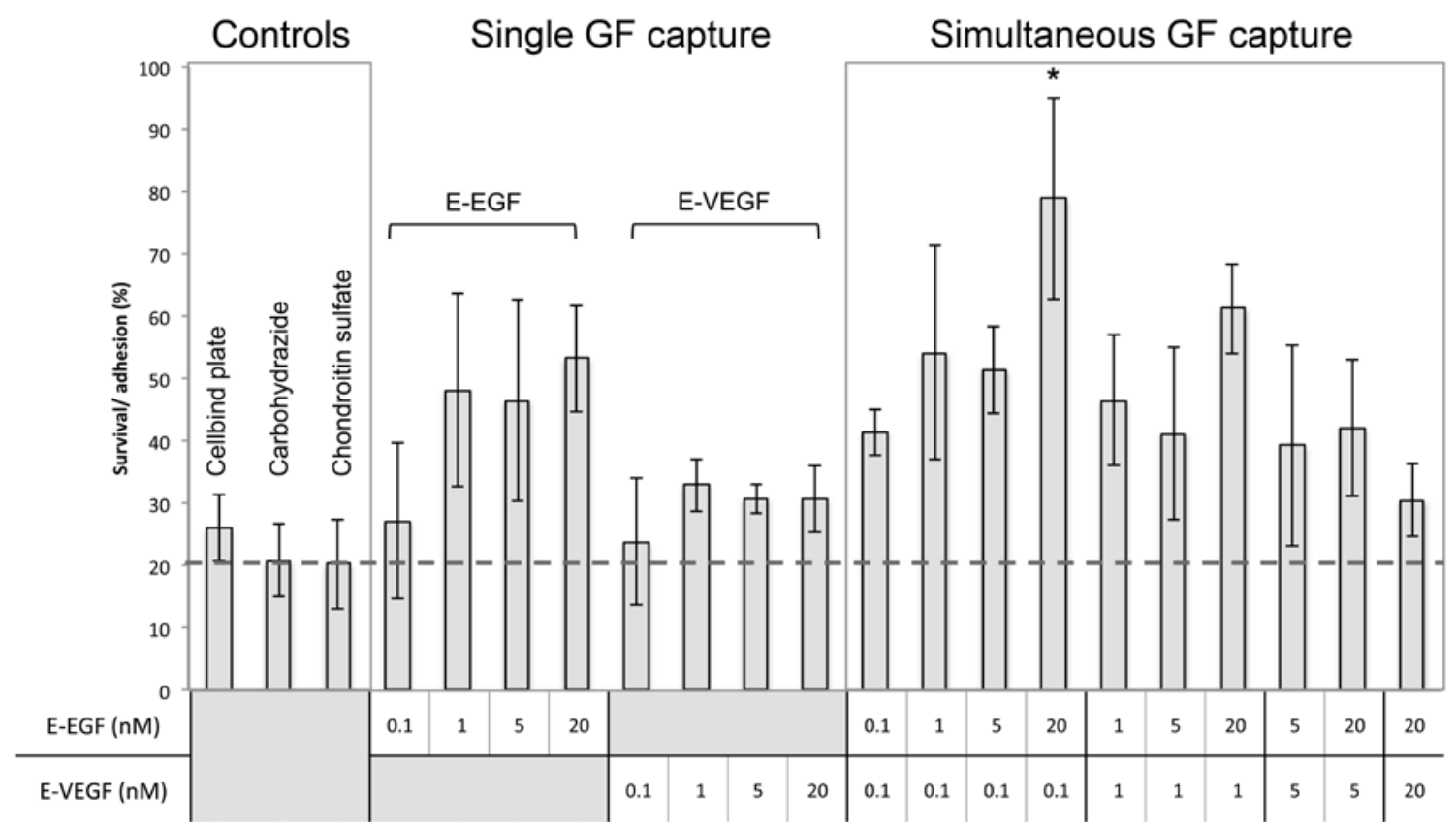

Figure 7. AoSMC survival after 7 days in serum-free medium. Ratio of metabolic activity estimated by resazurin assay at 7 days compared to initial adhesion (Mean $\pm S D ; n=$ 12). *: Statistical difference with all other conditions $(p<0.005)$, except with the coincubation of E-EGF $20 \mathrm{nM}$ and E-VEGF $1 \mathrm{nM}$, ( $p=0.18)$.

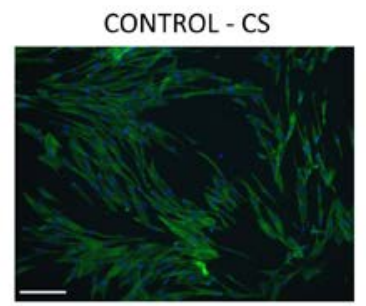

Survival: $20 \%$

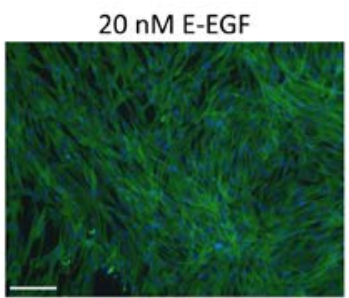

Survival: $53 \%$

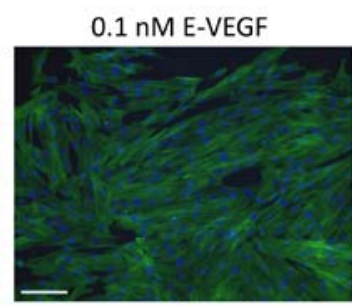

Survival: $24 \%$

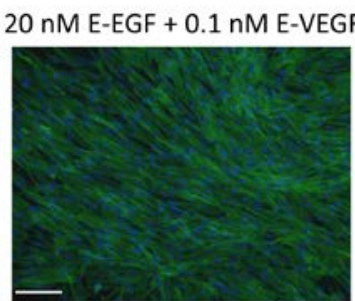

Survival: $79 \%$

Figure 8. Morphology of AoSMC after 7 days in serum-free medium, actin and nucleus staining. Scale bar: $200 \mu \mathrm{m}$. 
Once again, a further increase in cell survival was observed for surfaces incubated with a mixture of GFs. Thus, the combination of $20 \mathrm{nM}$ E-EGF and $0.1 \mathrm{nM}$ E-VEGF led to $79 \pm 16 \%$ cell retention after 7 days in serum-free medium, whereas 20 nM E-EGF and $0.1 \mathrm{nM}$ E-VEGF separately induced $53 \pm 9 \%$ and $24 \pm 10 \%$ cell survival, respectively. The pro-survival effect induced by this specific GF ratio was statistically higher than all others we tested ( $p<0.005$ ), except for the combination of 20 nM E-EGF and 1 nM E-VEGF (62 $\pm 7 \%, p=0.18)$.

Of interest, on surfaces incubated with $0.1 \mathrm{nM}$ E-VEGF, cell survival was lower than on 20 nM E-EGF and 20 nM E-EGF + 0.1 nM E-VEGF (Figs. 7 and 8). However, the cell spreading (Table 2) was also higher on this surface $(p<0.05)$, so that the surface coverage by cells appeared relatively similar on the three surfaces (Fig. 8). On CS, cell survival was similar to $0.1 \mathrm{nM}$ E-VEGF, but cell spreading was lower, leading to a less extensive surface coverage.

Table 2. AoSMC single cell area after 7 days in serum-free medium (mean + SD). *: Statistical difference with $20 \mathrm{nM}$ E-EGF and $20 \mathrm{nM}$ E-EGF + $0.1 \mathrm{nM}$ E-VEGF conditions $(p<0.05)$.

\begin{tabular}{|c|c|c|c|c|}
\hline Surface & CS & 20 nM E-EGF & 0.1 nM E-VEGF & $\begin{array}{c}20 \text { nM E-EGF + } \\
0.1 \text { nM E-VEGF }\end{array}$ \\
\hline $\begin{array}{c}\text { AoSMC area } \\
\left(\mu \mathrm{m}^{2}\right)\end{array}$ & $2394 \pm 160$ & $2001 \pm 97$ & $3183 \pm 439 *$ & $1864 \pm 91$ \\
\hline
\end{tabular}




\section{DISCUSSION}

The characterization of bioactive surfaces involving grafted GFs is important to understand their biological outcomes. In this study, ELISA was used to assess the amounts of captured of Ecoil-tagged GFs on Kcoil-functionalized CS surfaces. ELISA is a common method to characterize GF immobilization.[5, 8, 17, 50] However, in our case, the signal collected in direct ELISA was only semi quantitative since a saturation was observed for incubation concentrations higher than $5 \mathrm{nM}$ and $1 \mathrm{nM}$ for E-EGF and EVEGF, respectively (Fig. 2). Several studies using a similar direct ELISA method did not report any saturation of the signal,[17, 50, 51] while in contrast, Shen et al. also observed a detection limit of direct ELISA for samples with high quantities of covalently immobilized VEGF in a collagen scaffold.[8] Our first hypothesis is that the saturation was due to steric hindrance of anti-EGF antibodies, anti-VEGF antibodies or horseradish peroxidase enzyme. This suggests that the coil-coil system enabled to achieve high GF surface densities. Indeed, in a previous study, we observed that the coiled-coil mediated EGF immobilization allowed higher capture efficiencies compared to covalent grafting.[37] Another explanation for the signal saturation we observed, especially in the case of E-VEGF, could be a saturation of the Kcoil units on CS, since the secondary capture of E-EGF on surfaces pre-incubated with E-VEGF at concentrations higher than

$5 \mathrm{nM}$ did not occur (Fig. 3). Despite these limitations in GF quantification due to signal saturation, our results unambiguously showed that the coiled-coil tethering strategy enabled the oriented immobilization of two GFs at different surface densities on CS via a simultaneous incubation. 
As stated in the introduction, several studies have explored the potential benefits of GF combination, either by covalent grafting,[20, 24] progressive release from a polymer scaffolds or nanoparticles,[15, 16, 19, 21] capture by matrix[23] or oriented tethering.[17] To our knowledge, most studies were however focused on testing combinations of different GF at fixed concentrations, rather than varying their relative amounts and studying the biological effect brought by specific ratios. Recently, Almodovar and colleagues have used a microfluidic device to study the effect of gradients of BMP-2 and BMP-7 in layer-by-layer films of poly(L-lysine) and hyaluronan. The authors have observed an additive or synergistic effect of both GFs for myoblast differentiation.[23] Our coiled-coil based strategy, in addition to ensuring an oriented and stable GF display, allowed us to control the captured amounts of each of them by simply adjusting their concentration within the incubation mix ('simultaneous incubation'). This is of salient interest since we did not only demonstrate the benefits of GF combination but also that the HUVEC and AoSMC responses were maximal for distinct combinations of GF amounts (Figs. 5 and 6).

Indeed, the combination of EGF and VEGF increased the biological response of both HUVEC and AoSMC when compared to each GF being tethered separately. Specific ratios of GFs allowed maximal efficiency either for AoSMC survival (20 nM E-EGF + $0.1 \mathrm{nM}$ E-VEGF) or for HUVEC survival (20 nM E-EGF + 5 nM E-VEGF), suggesting that this approach is an interesting strategy to fine-tune cell response around vascular implants or tissue engineering scaffolds. 
Two hypotheses can be drawn to explain the observed synergy. Our first hypothesis is that co-immobilized GFs simultaneously interact with their respective cell receptors and this co-stimulation triggers enhanced cells survival. Indeed, in the literature, both GFs are known to trigger PI3K/Akt and RAS/ERK pathways involved in cell survival.[52-54] The observed synergy could thus be due to the increased signaling in these pathways via simultaneous EGF receptor and VEGF receptor activation, leading to an increased cell response. In a recent study, Assal et al. have shown that a combination of bFGF, EGF and VEGF led to higher angiogenesis than isolated GFs, however their study did not specifically study EGF/VEGF synergy in detail.[17]

In the case of AoSMC, this hypothesis is supported by the fact that both GFs enhanced cell survival (Fig. 7). Separately, E-VEGF and E-EGF enhanced survival by up to $15 \%$ and $35 \%$, respectively, whereas their optimal combination enhanced survival by $60 \%$ compared to control surfaces. This hypothesis is however less plausible in the case of the HUVEC given that, in contrast to a report by Yang et al.,[55] our results did not show that E-EGF alone was sufficient to trigger survival. The influence of EGF on HUVEC has been debated in the literature. Some studies state that non-tumor endothelial cells do not possess EGF receptors, or at least that EGFR is not expressed at levels that are high enough for detection.[56, 57] On the contrary, Semino et al. identified that the EGF signaling cascade is essential to promote VEGF-induced morphogenesis of HUVEC and that, while the VEGF pathway stimulates HUVEC proliferation, the EGF pathway influences HUVEC migration.[58] The synergy observed with E-EGF and E-VEGF on HUVEC survival is thus difficult to relate to the EGF receptor activation. 
This brings us to our second hypothesis, which is centered on the spatial organization of our immobilized GF on the surface. One GF, although possessing little or no bioactivity on the targeted cells, could enhance the spatial orientation of the second GF by acting as a 'filler' on the surface, which may in turn favour the interactions between the other GF and cell receptors. This phenomenon of a bioinert species allowing an active protein to reach higher activity has previously been observed by Kumada et al.[59]

To precisely establish the role of both GFs in the observed synergy, a thorough examination of activated pathways would be necessary, for example by quantifying the levels of activation of PI3K/Akt and RAS/ERK in cells which EGF or VEGF receptors would have been previously blocked.

In the system we have here explored, E-EGF and E-VEGF immobilization was stable enough for us to observe a sustained AoSMC survival for 7 days, despite repeated medium changes. As presented in Fig. 4, the stability of E-VEGF was higher than that of E-EGF, probably due to the presence of two Ecoil-moieties on the E-VEGF homodimer, that leads to a higher avidity of the Kcoil-functionalized surface and a lower probability of release since both coiled-coil complexes would have to detach simultaneously for the E-VEGF to be released. Despite the lower E-EGF stability observed in Fig. 4 compared to E-VEGF, immobilized E-EGF was able to induce AoSMC survival over 7 days for incubation concentrations as low as $1 \mathrm{nM}$ (Fig. 7). Compared to other coiled-coil systems, our approach has the advantage to be more stable (characterized by a dissociation constant, $\mathrm{K}_{\mathrm{d}}$, of $6.10^{-11} \mathrm{M}$ [60]) compared to (i) natural affinity of GF for ECM components (e.g. VEGF affinity for heparin is characterized by a $K_{d}$ of $2.10^{-8} \mathrm{M}$ 
calculated from [61]), and (ii) the coiled-coil structures used by Assal et al. [17] developped by O'Shea et al. ( $\mathrm{K}_{\mathrm{d}}$ of $3 \cdot 10^{-8} \mathrm{M}$ calculated from [62]). The especially high affinity observed for the Ecoil/Kcoil system could prevent surface degradation upon GF/cell receptor interaction since the affinity of VEGF with its receptor is lower than the Ecoil/Kcoil affinity ( $\mathrm{K}_{\mathrm{d}}$ of $4.10^{-10}$ calculated from [61]).

Of interest, our system is very adaptable, allowing the stability of protein tethering to be tailored for precise clinical needs by changing the motif of the Kcoil or Ecoil units. More precisely, the stability of the coiled-coil structure can be lowered by shortening the amino acid sequence[60,63] or substituting selected residues in the hydrophobic core.[64] Controlled, progressive release of multiple GFs with different kinetics could thus be achieved, if needed. This could prove very interesting to mimic human tissue healing, where multiple GFs act successively.[12, 65]

\section{CONCLUSION}

This work highlights the potential of coiled-coil oriented tethering for coimmobilization of multiple GFs so as to optimize biological properties of surfaces for specific needs. Our results with the co-immobilization of EGF and VEGF on CS clearly demonstrated the possibility to adjust GF immobilization to direct a particular cell response, here the survival of endothelial or smooth muscle cells. Our work also highlights the use of our coiled-coil tethering system as a platform to help understand possible redundancy, competition or synergy existing among GFs towards the creation of smart biomaterials controlling the fate of targeted cells. 
Of prime interest, the simultaneous capture of the two GFs allowed us to reach higher levels of cell survival when compared to each GF being captured on its own. These promising results suggest a synergy between EGF and VEGF to trigger survival pathways. A possible application of the coiled-coil co-immobilization of EGF and VEGF could be the design of coatings for vascular grafts improving SMC survival on the abluminal side and HUVEC survival on the luminal side.

\section{ACKNOWLEDGEMENTS}

The authors would like to thank Samantha Noel for her judicious comments during manuscript writing and her help with cell area measurements. This study was funded jointly by the Canadian Institutes of Health Research (CIHR) (CPG 127764) and the Natural Sciences and Engineering Research Council of Canada (NSERC)(PRCS 446571).

\section{References}

[1] Formiga FR, Pelacho B, Garbayo E, Abizanda G, Gavira JJ, Simon-Yarza T, Mazo M, Tamayo E, Jauquicoa C, Ortiz-de-Solorzano C, Prósper F, Blanco-Prieto MJ. Sustained release of VEGF through PLGA microparticles improves vasculogenesis and tissue remodeling in an acute myocardial ischemia-reperfusion model. J Control Release 2010;147:30-7.

[2] Babensee J, McIntire L, Mikos A. Growth Factor Delivery for Tissue Engineering. Pharm Res 2000;17:497-504.

[3] Vulic K, Shoichet MS. Affinity-Based Drug Delivery Systems for Tissue Repair and Regeneration. Biomacromolecules 2014;15:3867-80.

[4] Pompe T, Salchert K, Alberti K, Zandstra P, Werner C. Immobilization of growth factors on solid supports for the modulation of stem cell fate. Nat Protocols 2010;5:1042-50.

[5] Masters KS. Covalent growth factor immobilization strategies for tissue repair and regeneration. Macromol Biosci 2011;11:1149-63. 
[6] Mieszawska A, Kaplan D. Smart biomaterials - regulating cell behavior through signaling molecules. BMC Biol 2010;8:59.

[7] Klenkler BJ, Dwivedi D, West-Mays JA, Sheardown H. Corneal epithelial cell adhesion and growth on EGF-modified aminated PDMS. Journal of Biomedical Materials Research Part A 2010;93A:1043-9.

[8] Shen YH, Shoichet MS, Radisic M. Vascular endothelial growth factor immobilized in collagen scaffold promotes penetration and proliferation of endothelial cells. Acta biomaterialia 2008;4:477-89.

[9] Stringa E, Knauper V, Murphy G, Gavrilovic J. Collagen degradation and plateletderived growth factor stimulate the migration of vascular smooth muscle cells. J Cell Sci 2000;113:2055-64.

[10] Galas RJ, Jr., Liu JC. Surface density of vascular endothelial growth factor modulates endothelial proliferation and differentiation. J Cell Biochem 2014;115:111-20.

[11] Uebersax L, Merkle HP, Meinel L. Insulin-like growth factor I releasing silk fibroin scaffolds induce chondrogenic differentiation of human mesenchymal stem cells. J Control Release 2008;127:12-21.

[12] Barrientos S, Stojadinovic O, Golinko MS, Brem H, Tomic-Canic M. Growth factors and cytokines in wound healing. Wound Repair Regen 2008;16:585-601. [13] Bennett NT, Schultz GS. Growth factors and wound healing: Biochemical properties of growth factors and their receptors. The American Journal of Surgery 1993;165:728-37.

[14] Risau W. Mechanisms of angiogenesis. Nature 1997;386:671-4.

[15] Chen F-M, Zhang M, Wu Z-F. Toward delivery of multiple growth factors in tissue engineering. Biomaterials 2010;31:6279-308.

[16] Sun G, Shen Y-I, Kusuma S, Fox-Talbot K, Steenbergen CJ, Gerecht S. Functional neovascularization of biodegradable dextran hydrogels with multiple angiogenic growth factors. Biomaterials 2011;32:95-106.

[17] Assal Y, Mie M, Kobatake E. The promotion of angiogenesis by growth factors integrated with ECM proteins through coiled-coil structures. Biomaterials 2013;34:3315-23.

[18] Wylie RG, Ahsan S, Aizawa Y, Maxwell KL, Morshead CM, Shoichet MS. Spatially controlled simultaneous patterning of multiple growth factors in three-dimensional hydrogels. Nat Mater 2011;10:799-806.

[19] Richardson TP, Peters MC, Ennett AB, Mooney DJ. Polymeric system for dual growth factor delivery. Nat Biotechnol 2001;19:1029-34.

[20] Chiu LLY, Radisic M. Scaffolds with covalently immobilized VEGF and Angiopoietin-1 for vascularization of engineered tissues. Biomaterials 2010;31:22641.

[21] Hao X, Silva EA, Mansson-Broberg A, Grinnemo KH, Siddiqui AJ, Dellgren G, Wardell E, Brodin LA, Mooney DJ, Sylven C. Angiogenic effects of sequential release of VEGF-A165 and PDGF-BB with alginate hydrogels after myocardial infarction. Cardiovasc Res 2007;75:178-85.

[22] Zieris A, Prokoph S, Levental KR, Welzel PB, Grimmer M, Freudenberg U, Werner C. FGF-2 and VEGF functionalization of starPEG-heparin hydrogels to 
modulate biomolecular and physical cues of angiogenesis. Biomaterials 2010;31:7985-94.

[23] Almodovar J, Guillot R, Monge C, Vollaire J, Selimovic S, Coll JL, Khademhosseini A, Picart C. Spatial patterning of BMP-2 and BMP-7 on biopolymeric films and the guidance of muscle cell fate. Biomaterials 2014;35:3975-85.

[24] Stefonek-Puccinelli T, Masters K. Co-Immobilization of Gradient-Patterned Growth Factors for Directed Cell Migration. Ann Biomed Eng 2008;36:2121-33. [25] Ito Y, Tada S. Bio-orthogonal and combinatorial approaches for the design of binding growth factors. Biomaterials 2013;34:7565-74.

[26] Ito Y, Shu Qin L, Imanishi Y. Enhancement of cell growth on growth factorimmobilized polymer film. Biomaterials 1991;12:449-53.

[27] Boucher C, Ruiz J-C, Thibault M, Buschmann MD, Wertheimer MR, Jolicoeur M, Durocher Y, De Crescenzo G. Human corneal epithelial cell response to epidermal growth factor tethered via coiled-coil interactions. Biomaterials 2010;31:7021-31. [28] Joddar B, Ito Y. Biological modifications of materials surfaces with proteins for regenerative medicine. J Mater Chem 2011;21:13737.

[29] Rusmini F, Zhong Z, Feijen J. Protein Immobilization Strategies for Protein Biochips. Biomacromolecules 2007;8:1775-89.

[30] Nishi N, Matsushita O, Yuube K, Miyanaka H, Okabe A, Wada F. Collagen-binding growth factors: production and characterization of functional fusion proteins having a collagen-binding domain. Proceedings of the National Academy of Sciences 1998;95:7018-23.

[31] Ishikawa T, Terai H, Kitajima T. Production of a biologically active epidermal growth factor fusion protein with high collagen affinity. J Biochem 2001;129:627-33. [32] Kitajima T, Sakuragi M, Hasuda H, Ozu T, Ito Y. A chimeric epidermal growth factor with fibrin affinity promotes repair of injured keratinocyte sheets. Acta biomaterialia 2009;5:2623-32.

[33] Sakuragi M, Kitajima T, Nagamune T, Ito Y. Recombinant hBMP4 incorporated with non-canonical amino acid for binding to hydroxyapatite. Biotechnol Lett 2011;33:1885-90.

[34] Boucher C, Liberelle B, Jolicoeur M, Durocher Y, De Crescenzo G. Epidermal Growth Factor Tethered through Coiled-Coil Interactions Induces Cell Surface Receptor Phosphorylation. Bioconjug Chem 2009;20:1569-77.

[35] Boucher C, St-Laurent G, Loignon M, Jolicoeur M, De Crescenzo G, Durocher Y. The Bioactivity and Receptor Affinity of Recombinant Tagged EGF Designed for Tissue Engineering Applications Is Defined by the Nature and Position of the Tags. Tissue Engineering Part A 2008;14:2069-77.

[36] Murschel F, Liberelle B, St-Laurent G, Jolicoeur M, Durocher Y, De Crescenzo G. Coiled-coil-mediated grafting of bioactive vascular endothelial growth factor. Acta biomaterialia 2013;9:6806-13.

[37] Lequoy P, Liberelle B, De Crescenzo G, Lerouge S. Additive benefits of chondroitin sulfate and oriented tethered epidermal growth factor for vascular smooth muscle cell survival. Macromol Biosci 2014;14:720-30.

[38] Oh SH, Ward CL, Atala A, Yoo JJ, Harrison BS. Oxygen generating scaffolds for enhancing engineered tissue survival. Biomaterials 2009;30:757-62. 
[39] Li Z, Guo X, Guan J. An oxygen release system to augment cardiac progenitor cell survival and differentiation under hypoxic condition. Biomaterials 2012;33:591423.

[40] Henderson EL, Gang YJ, Sukhova GK, Whittemore AD, Knox J, Libby P. Death of smooth muscle cells and expression of mediators of apoptosis by T lymphocytes in human abdominal aortic aneurysms. Circulation 1999;99:96-104. [41] Durdu S, Deniz GC, Balci D, Zaim C, Dogan A, Can A, Akcali KC, Akar AR. Apoptotic Vascular Smooth Muscle Cell Depletion via BCL2 Family of Proteins in Human Ascending Aortic Aneurysm and Dissection. Cardiovasc Ther 2012;30:30816.

[42] Keuren JFW, Wielders SJH, Willems GM, Morra M, Cahalan L, Cahalan P, Lindhout T. Thrombogenicity of polysaccharide-coated surfaces. Biomaterials 2003;24:1917-24.

[43] Thalla PK, Fadlallah H, Liberelle B, Lequoy P, De Crescenzo G, Merhi Y, Lerouge S. Chondroitin sulfate coatings display low platelet but high endothelial cell adhesive properties favorable for vascular implants. Biomacromolecules 2014;15:2512-20. [44] Noel S, Hachem A, Merhi Y, De Crescenzo G. Development of a Polyester Coating Combining Antithrombogenic and Cell Adhesive Properties: Influence of Sequence and Surface Density of Adhesion Peptides. Biomacromolecules 2015;16:1682-94. [45] Charbonneau C, Liberelle B, Hébert M-J, De Crescenzo G, Lerouge S. Stimulation of cell growth and resistance to apoptosis in vascular smooth muscle cells on a chondroitin sulfate/epidermal growth factor coating. Biomaterials 2011;32:1591600.

[46] Murschel F, Liberelle B, St-Laurent G, Jolicoeur M, Durocher Y, De Crescenzo G. Coiled-coil-mediated grafting of bioactive vascular endothelial growth factor. Acta Biomater 2013;9:6806-13.

[47] Boucher C, St-Laurent G, Loignon M, Jolicoeur M, De Crescenzo G, Durocher Y. The bioactivity and receptor affinity of recombinant tagged EGF designed for tissue engineering applications is defined by the nature and position of the tags. Tissue Eng Part A 2008;14:2069-77.

[48] Charbonneau C, Ruiz JC, Lequoy P, Hebert MJ, De Crescenzo G, Wertheimer MR, Lerouge S. Chondroitin Sulfate and Epidermal Growth Factor Immobilization after Plasma Polymerization: A Versatile Anti-Apoptotic Coating to Promote Healing Around Stent Grafts. Macromol Biosci 2012;12:812-21.

[49] Raymond MA, Desormeaux A, Laplante P, Vigneault N, Filep JG, Landry K, Pshezhetsky AV, Hebert MJ. Apoptosis of endothelial cells triggers a caspasedependent anti-apoptotic paracrine loop active on vascular smooth muscle cells. FASEB J 2004;18:U166-U84.

[50] Crombez M, Chevallier P, Petitclerc E, Mantovani D, Laroche G. Improving arterial prosthesis neo-endothelialization: application of a proactive VEGF construct onto PTFE surfaces. Biomaterials 2005;26:7402-9.

[51] Anderson SM, Chen TT, Iruela-Arispe ML, Segura T. The phosphorylation of vascular endothelial growth factor receptor-2 (VEGFR-2) by engineered surfaces with electrostatically or covalently immobilized VEGF. Biomaterials 2009;30:461828. 
[52] Dreux AC, Lamb DJ, Modjtahedi H, Ferns GAA. The epidermal growth factor receptors and their family of ligands: Their putative role in atherogenesis.

Atherosclerosis 2006;186:38-53.

[53] Ciardiello F, Troiani T, Bianco R, Orditura M, Morgillo F, Martinelli E, Morelli

$\mathrm{MP}$, Cascone T, Tortora G. Interaction between the epidermal growth factor receptor (EGFR) and the vascular endothelial growth factor (VEGF) pathways: a rational approach for multi-target anticancer therapy. Ann Oncol 2006;17 Suppl 7:vii109-14. [54] Hung HS, Wu CC, Chien S, Hsu SH. The behavior of endothelial cells on polyurethane nanocomposites and the associated signaling pathways. Biomaterials 2009;30:1502-11.

[55] Yang B, Zhou L, Peng B, Sun Z, Dai Y, Zheng J. In vitro comparative evaluation of recombinant growth factors for tissue engineering of bladder in patients with neurogenic bladder. J Surg Res 2014;186:63-72.

[56] Amin DN, Hida K, Bielenberg DR, Klagsbrun M. Tumor Endothelial Cells Express Epidermal Growth Factor Receptor (EGFR) but not ErbB3 and Are Responsive to EGF and to EGFR Kinase Inhibitors. Cancer Res 2006;66:2173-80.

[57] Hirata A, Ogawa S-i, Kometani T, Kuwano T, Naito S, Kuwano M, Ono M. ZD1839 (Iressa) induces antiangiogenic effects through inhibition of epidermal growth factor receptor tyrosine kinase. Cancer Res 2002;62:2554-60.

[58] Semino CE, Kamm RD, Lauffenburger DA. Autocrine EGF receptor activation mediates endothelial cell migration and vascular morphogenesis induced by VEGF under interstitial flow. Exp Cell Res 2006;312:289-98.

[59] Kumada Y, Shiritani Y, Hamasaki K, Ohse T, Kishimoto M. High biological activity of a recombinant protein immobilized onto polystyrene. Biotechnology Journal 2009;4:1178-89.

[60] De Crescenzo G, Litowski JR, Hodges RS, O'Connor-McCourt MD. Real-time monitoring of the interactions of two-stranded de novo designed coiled-coils: Effect of chain length on the kinetic and thermodynamic constants of binding.

Biochemistry 2003;42:1754-63.

[61] Anderson SM, Shergill B, Barry ZT, Manousiouthakis E, Chen TT, Botvinick E, Platt MO, Iruela-Arispe ML, Segura T. VEGF internalization is not required for VEGFR-2 phosphorylation in bioengineered surfaces with covalently linked VEGF. Integrative biology 2011;3:887-96.

[62] O'Shea EK, Lumb KJ, Kim PS. Peptide 'Velcro': design of a heterodimeric coiled coil. Curr Biol 1993;3:658-67.

[63] Litowski JR, Hodges RS. Designing heterodimeric two-stranded alpha-helical coiled-coils: the effect of chain length on protein folding, stability and specificity. J

Pept Res 2001;58:477-92.

[64] Litowski JR, Hodges RS. Designing Heterodimeric Two-stranded $\alpha$-Helical Coiled-coils: effects of hydrophobicity and $\alpha$-helical propensity on protein folding, stability, and specificity J Biol Chem 2002;277:37272-9.

[65] Rice JJ, Martino MM, De Laporte L, Tortelli F, Briquez PS, Hubbell JA.

Engineering the Regenerative Microenvironment with Biomaterials. Advanced

Healthcare Materials 2013;2:57-71. 

Supplementary Figure

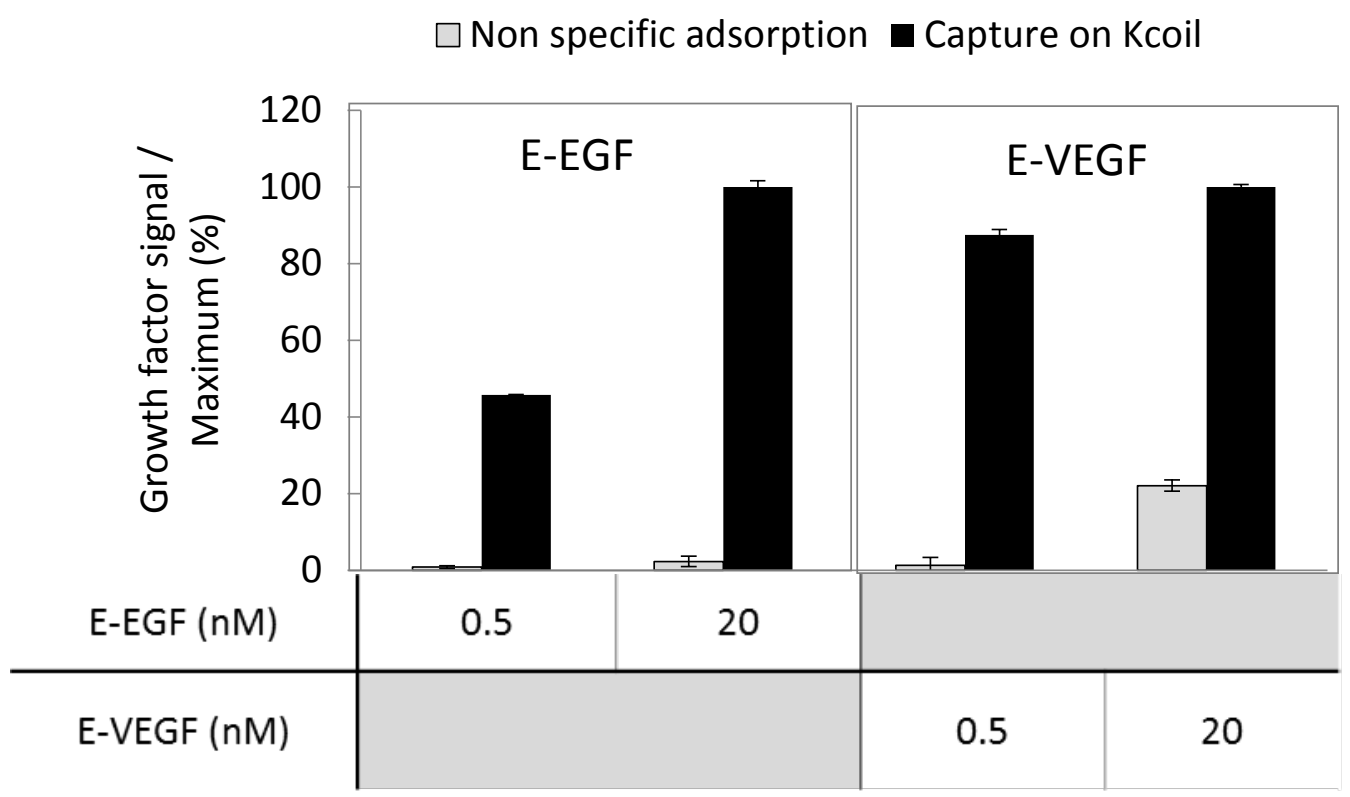

Supplementary Figure 1. Non specific adsorption and coiled-coil mediated capture of EEGF and E-VEGF on chondroitin sulfate. Relative ELISA signal as a function of growth factor incubation concentrations (Mean $\pm S D, n \geq 4$ ). 